\title{
Black race as a predictor of poor health outcomes among a national cohort of HIVIAIDS patients admitted to US hospitals: a cohort
} study

\author{
Christine U Oramasionwu ${ }^{1,2}$, Jonathan M Hunter², Jeff Skinner ${ }^{3}$, \\ Laurajo Ryan ${ }^{1,2}$, Kenneth A Lawson ${ }^{1}$, Carolyn M Brown ${ }^{1}$, Brittany R Makos ${ }^{1,2}$ \\ and Christopher R Frei ${ }^{* 1,2}$
}

Address: ${ }^{1}$ College of Pharmacy, The University of Texas, Austin, TX, USA, ${ }^{2}$ Department of Medicine, The University of Texas Health Science Center, San Antonio, TX, USA and ${ }^{3}$ The National Institute of Allergy and Infectious Diseases, The National Institutes of Health, Bethesda, MD, USA

Email: Christine U Oramasionwu - chrorams@mail.utexas.edu; Jonathan M Hunter - jonathan.hunter@gmail.com;

Jeff Skinner - skinnerj@niaid.nih.gov; Laurajo Ryan - ryanl@uthscsa.edu; Kenneth A Lawson - kenlawson@mail.utexas.edu;

Carolyn M Brown - cmbrown@mail.utexas.edu; Brittany R Makos - brittany.rose@gmail.com; Christopher R Frei* - freic@uthscsa.edu

* Corresponding author

Published: II August 2009

BMC Infectious Diseases 2009, 9:127 doi:10.1 186/1471-2334-9-127
Received: 7 January 2009

Accepted: II August 2009

This article is available from: http://www.biomedcentral.com/I47I-2334/9//27

(C) 2009 Oramasionwu et al; licensee BioMed Central Ltd.

This is an Open Access article distributed under the terms of the Creative Commons Attribution License (http://creativecommons.org/licenses/by/2.0), which permits unrestricted use, distribution, and reproduction in any medium, provided the original work is properly cited.

\begin{abstract}
Background: In general, the Human Immunodeficiency Virus/Acquired Immunodeficiency Syndrome (HIV/AIDS) population has begun to experience the benefits of highly active antiretroviral therapy (HAART); unfortunately, these benefits have not extended equally to Blacks in the United States, possibly due to differences in patient comorbidities and demographics. These differences include rates of hepatitis $B$ and $C$ infection, substance use, and socioeconomic status. To investigate the impact of these factors, we compared hospital mortality and length of stay (LOS) between Blacks and Whites with HIVIAIDS while adjusting for differences in these key characteristics.

Methods: The 1996-2006 National Hospital Discharge Surveys were used to identify HIVIAIDS patients admitted to US hospitals. Survey weights were incorporated to provide national estimates. Patients $<18$ years of age, those who left against medical advice, those with an unknown discharge disposition and those with a LOS < I day were excluded. Patients were stratified into subgroups by race (Black or White). Two multivariable logistic regression models were constructed with race as the independent variable and outcomes (mortality and LOS > 10 days) as the dependent variables. Factors that were significantly different between Blacks and Whites at baseline via bivariable statistical tests were included as covariates.

Results: In the general US population, there are approximately 5 times fewer Blacks than Whites. In the present study, I.5 million HIVIAIDS hospital discharges were identified and Blacks were 6 times more likely to be hospitalized than Whites. Notably, Blacks had higher rates of substance use $(30 \%$ vs. $24 \%$; $P<0.001)$, opportunistic infections ( $27 \%$ vs. $26 \% ; P<0.00 I)$ and cocaine use $(13 \%$ vs. $5 \% ; P<0.001)$. Conversely, fewer Blacks were co-infected with hepatitis $C$ virus ( $8 \%$ vs. $12 \% ; P<0.001$ ). Hepatitis $B$ virus was relatively infrequent ( $3 \%$ for both groups). Crude mortality rates were similar for both cohorts (5\%); however, a greater proportion of Blacks had a LOS $>10$ days $(21 \%$ vs. $19 \% ; P<0.00 \mathrm{I})$. Black race, in the presence of comorbidities, was correlated with a higher odds of LOS $>10$ days (OR, $95 \% \mathrm{Cl}=1.20$ [1.10-1.30]), but was not significantly correlated with a higher odds of mortality (OR, 95\% Cl = 1.07 [0.93-1.25]).
\end{abstract}

Conclusion: Black race is a predictor of LOS > 10 days, but not mortality, among HIVIAIDS patients admitted to US hospitals. It is possible that racial disparities in hospital outcomes may be closing with time. 


\section{Background}

Human Immunodeficiency Virus (HIV) has had a devastating impact on the United States, and the effects are far reaching. Each year in the United States, HIV infects over 56,000 people and claims upwards of 14,000 lives $[1,2]$. Despite these grim statistics, there has been considerable progress made in curbing the detrimental impact of the epidemic. The introduction of antiretroviral therapy in the late 1980s was the inaugural event in the therapeutic management of HIV patients, and led to lower rates of HIVrelated morbidity and mortality [3]. Moreover, the advent of highly-active antiretroviral therapy (HAART) over a decade ago resulted in even greater reductions in HIVrelated hospitalizations and mortality [4,5]. While HAART has decreased overall morbidity and mortality in the general HIV population, the benefits of these advances have not extended equally to the Black segment of the community [6-9].

Many Blacks may first seek care late in the course of their disease, after they have already become symptomatic with an opportunistic infection (OI) $[10,11]$. Because of this late diagnosis, they are at higher risk for an Acquired Immunodeficiency Syndrome (AIDS) diagnosis when they are found to be HIV positive, which may require immediate hospital admission [12]. Black patients may then experience longer hospitalizations and higher mortality rates than White patients [13-17]. These disparities in health outcomes between Black and White HIV patients may not be attributable to an imbalance in the receipt of HAART [18].

The presence of these comorbidities may worsen the overall health outcomes of those patients with advanced HIV/ AIDS disease even when equivalent therapy is provided [18-22]. Substance use, hepatitis B virus (HBV), hepatitis $\mathrm{C}$ virus (HCV), and sexually transmitted infections (STIs) have all been linked to increased transmission of HIV, and can potentially complicate the course of the HIV disease [19,21,23-26]. These disparities between the Black HIV/ AIDS population and the non-Black HIV/AIDS population are of critical importance; a deeper understanding of the impact of these disparities in Blacks is needed. To further this understanding, the present study evaluated health outcomes among HIV/AIDS patients in the 19962006 National Hospital Discharge Survey (NHDS). This study sought to: (1) compare health outcomes (mortality and length of hospital stay [LOS > 10 days]) between Black and White patients; (2) describe changes in health outcomes for Black and White patients over time in the HAART era; and, (3) quantify baseline rates of OIs, substance use, HBV, HCV, and STIs for Black and White patients.

\section{Methods \\ Data source}

Hospital discharge data were extracted from the 19962006 NHDS, a series of annual national surveys conducted by the National Center for Health Statistics (NCHS) of the Centers for Disease Control and Prevention (CDC) [27]. The NHDS has been conducted annually since 1965 by the NCHS. The NHDS are a series of voluntary nationwide sample surveys completed by short-stay hospitals in the United States. The NHDS collects information from non-federal hospitals (excluding military, Department of Veterans Affairs, and other federal facilities such as prison hospitals) in the United States. The US Bureau of the Census is the agent for data collection for these surveys. The hospital staff in each facility are trained by Census personnel to complete the survey instruments. The units of analyses are national discharges rather than estimates for individual patients. Some patients may have multiple discharges from a particular hospital in a given year and the possibility exists that they may be sampled more than once, but due to the complexity of the survey sampling, multiple discharges for an individual patient in a given year are unlikely. National estimates of diagnoses and procedures are classified by International Classification of Diseases, Ninth Revision, Clinical Modification (ICD-9) codes. The overall error rate for records manually coded is estimated at one percent for hospital diagnoses, 0.7 percent for surgical and diagnostic procedures, and 0.2 percent for non-medical data entry [27]. Data from the NHDS surveys has been used to evaluate other areas of racial disparities and hospital outcomes [28-30].

\section{Study definitions}

An HIV/AIDS-associated hospitalization was defined as a hospitalization with at least one of the following ICD-9 codes for discharge diagnosis: 042-044 (HIV disease), V08 (asymptomatic HIV infection), or 079.53 (HIV-2 illness). ICD-9 codes were also collected for diagnoses of HBV, $\mathrm{HCV}$, substance use, sexually transmitted infections, and OIs (Table 1). OIs were identified using the conditions included in the 1993 AIDS surveillance case definition [31]. Opportunistic infections included: candidiasis, cocciodomycosis, coccidiosis (in place of isosporiasis), cryptosporidiosis, cryptococcosis, cytomegalovirus disease, histoplasmosis, Mycobacterium Avium, pneumocystosis, progressive multifocal leukoencephalopathy, Salmonella, Toxoplasmosis gondii, and tuberculosis [31,32]. Sexually transmitted infections included chlamydia, gential herpes, gonorrhea, herpes simplex virus, human papilloma virus, Lymphogranuloma venereum, pelvic inflammatory disease, syphilis, and trichomoniasis. All opportunistic infections were classified as either preventable with chemoprophylaxis (Mycobacterium Avium, pnuemocystosis and Toxoplasmosis gondii) or non-preventable with chemo- 
Table I: Codes for Diagnoses from International Classification of Diseases, 9th Revision, Clinical Modification (ICD-9-CM)

\begin{tabular}{|c|c|}
\hline ICD-9-CM Code & Diagnosis \\
\hline $042,044,043,079.53, \mathrm{~V} 08$ & Human Immunodeficiency Virus/Acquired Immune Deficiency Syndrome \\
\hline \multicolumn{2}{|c|}{ Opportunistic Infections } \\
\hline 112 & Candidiasis \\
\hline 114 & Coccidioidomycosis \\
\hline 007.2 & Coccidiosis (for Isosporiasis) \\
\hline 007.4 & Cryptosporidiosis \\
\hline 117.5 & Cryptococcosis \\
\hline 078.5 & Cytomegalovirus \\
\hline 115 & Histoplasmosis \\
\hline $031.0,031.2$ & Mycobacterium avium \\
\hline 136.3 & Pneumocystosis \\
\hline 046.3 & Progressive multifocal leukoencephalopathy \\
\hline 003 & Salmonella \\
\hline 130 & Toxoplasmosis gondii \\
\hline $010-018$ & Tuberculosis \\
\hline
\end{tabular}

Hepatitis

\begin{tabular}{cc}
$\begin{array}{c}070.41,070.44,070.5 I, \\
070.54,070.7\end{array}$ & Hepatitis C Virus \\
\hline $070.3,070.2$ & Hepatitis B Virus
\end{tabular}

Sexually Transmitted Infections

\begin{tabular}{cc}
\hline 099.0 & Chancroid \\
\hline 099.5 & Chlamydia \\
\hline 054 & Genital Herpes \\
\hline 098.11, V02.7 & Gonorrhea \\
\hline $078.1,079.4$, V73.8I & Human Papilloma Virus \\
\hline 099.1 & Lymphogranuloma venereum \\
\hline 614.9 & Pelvic inflammatory disease \\
\hline $091,092,093,094,095,095.7,095.8,095.9,096,097,097.1,097.9$ & Syphilis \\
\hline
\end{tabular}


Table I: Codes for Diagnoses from International Classification of Diseases, 9th Revision, Clinical Modification (ICD-9-CM) (Continued)

\begin{tabular}{|c|c|}
\hline 131 & Trichomoniasis \\
\hline \multicolumn{2}{|c|}{ Types of Substance Use } \\
\hline $303,305.0$ & Alcohol use \\
\hline $304.3,305.2$ & Cannabis use \\
\hline $304.2,305.6$ & Cocaine use \\
\hline $304.0,305.5$ & Opioid use \\
\hline 305.1 & Tobacco use \\
\hline 304.I, 305.4 & Sedative, hypnotic, or anxiolytic use \\
\hline $304.5,305.3$ & Hallucinogen use \\
\hline 305.7 & Amphetamine or related sympathomimetic abuse \\
\hline 305.8 & Anti-depressant type abuse \\
\hline 305.9 & Other, mixed, or unspecified drug abuse \\
\hline 304.4 & Amphetamine and other psychostimulant dependence \\
\hline 304.6 & Other specified drug dependence \\
\hline 304.8 & Combinations of drug dependence excluding opioid type drug \\
\hline 304.9 & Unspecified drug dependence \\
\hline 304.7 & Combinations of opioid type drug with any other \\
\hline
\end{tabular}

prophylaxis [33]. For the purpose of data analysis, collapsed categories were created for comorbidities that were reported infrequently. An "other substance use" category was created for types of substance use with a prevalence of $<1 \%$ and "other STI" for STIs $<1 \%$.

The NHDS surveys provide information about primary forms of hospital visit payment with standardized options. For the purposes of data analysis, the different forms of insurance were defined as uninsured (no charge or self-pay), government (Medicare, Medicaid, or other government form of payment), private (HMO/PPO, Blue Cross/Blue Shield, or other private insurance), and other/ unknown (workers compensation, other, or not stated).

\section{Study design}

This was a retrospective analysis of HIV/AIDS hospitalizations in the United States from 1996-2006. The University of Texas at Austin Institutional Review Board determined this protocol to be exempt (\#2009-03-0100). Data included patient demographics (age, race, ethnicity, gender, and marital status), year of discharge, insurance status, geographic location within the United States, hospital LOS, and discharge status. Patients who were $<18$ years, those who left against medical advice, those with an unknown discharge disposition, and those with a LOS $<1$ day were excluded from data analysis. Patient discharge weighting was incorporated into the dataset to provide national estimates across the United States.

Hospital mortality and LOS > 10 days were evaluated. Mortality was classified as an inpatient admission resulting in death. In order to incorporate survey weights, LOS was then dichotomized (mean LOS $\leq 10$ or $>10$ days) for all hospital discharges. This cut-off was chosen on the basis of the LOS distribution which demonstrated a peak of approximately 10 days. Chi-square tests were used to compare categorical baseline variables (survey year, age, gender, insurance status, and comorbid conditions) between races. Two multivariable logistic regression models were used to assess the impact of race (independent variable) on hospital mortality and LOS $>10$ days 
(dependent variables). Known predictors of poor health outcomes among HIV patients were entered simultaneously as covariates into both models. These included gender, insurance status, AIDS-related infections, and injection drug use $[9,34,35]$. The NHDS does not contain an ICD-9 code for 'injection drug use.' The most detailed ICD-9 code for heroin use was included under the umbrella heading of opioid use (which in addition to heroin also includes meperidine, morphine, and other opiates). To avoid grouping all types of substance abuse together, 'cocaine use' was considered a proxy for injection drug use. Likewise, variables that were statistically and clinically significant in chi-square analyses were also entered into both multivariable analyses as covariates. These variables included race, survey year, age, gender, insurance status, geographic region, presence of OI, HBV, $\mathrm{HCV}$, and cocaine use. All data were analyzed using JMP $7.0^{\circledR}$ (SAS Corp, Cary, NC) and an alpha-level of 0.05 was used to determine statistical significance.

\section{Results}

From 1996-2006, 1.5 million HIV/AIDS hospital discharges were identified. On average, 138,016 hospitalizations occurred each year. The mean patient age was 42 years and $67 \%$ of all patients were male. Blacks accounted for more hospitalizations than Whites (62\% vs. 38\%). A large proportion of patients had government insurance $(66 \%)$ or private insurance $(22 \%)$. Bivariable analyses (Table 2) revealed a greater proportion of Blacks were female (41\% vs. 21\%; $P<0.001)$. Chi-square analysis revealed a significant relationship between insurance status and race $(P<0.001)$; Blacks had a higher likelihood of having some form of government insurance (70\% vs. $58 \%$ ) and fewer Blacks than Whites had private insurance (18\% vs. $31 \%)$.

\section{Comorbidities between Black and White patients}

Substance use and OIs were present in 28\% and 27\% of all discharges, respectively; whereas $\mathrm{HCV}$, STIs, and $\mathrm{HBV}$ were reported in $10 \%, 5 \%$, and 3\%, respectively. Common forms of substance use included cocaine use $(9 \%)$, alcohol use (9\%), opioid use (9\%), and tobacco use $(6 \%)$. Herpes simplex was not commonly reported (3\%).

Results from bivariable analysis of characteristic differences between Blacks and Whites are reported in Table 2. A large proportion of both Black and White patients carried diagnoses for OIs ( $27 \%$ vs. $26 \% ; P<0.001)$. A significantly greater proportion of Blacks reported substance use $(30 \%$ vs. $24 \% ; P<0.001)$. Conversely, fewer patients in the Black cohort were co-infected with HCV based on ICD-9 codes ( $8 \%$ vs. $12 \% ; P<0.001)$. The remaining comorbidities were relatively infrequent among Blacks and Whites. Further analysis revealed significant differences for comorbid subtypes between the two cohorts.
Blacks, when compared to Whites, had a higher prevalence of non-preventable OI $(21 \%$ vs. $19 \% ; P<0.001)$, cocaine use (13\% vs. 5\%; $P<0.001)$, opioid use (9\% vs. $6 \% ; P<0.001)$, and alcohol use $(10 \%$ vs. $8 \% ; P<0.001)$.

\section{Hospital mortality between Black and White patients}

Overall, crude mortality rates were similar between Black and White cohorts 5\% vs. 5\% (OR 95\% CI =0.97 [0.96$0.99])$. Simple logistic regression analysis revealed the following variables $(P<0.001)$ to be associated with mortality: race, survey year, age, gender, insurance status, presence of an OI, HBV, HCV, STIs and cocaine use. All clinically relevant variables from the regression analysis were subsequently entered in the multivariable model as covariates. Results from the multivariable analyses are presented in Tables 3 and 4 . When significant predictors for mortality were entered into the model, Black race was not a significant independent predictor of mortality (OR, $95 \%$ CI $=1.07$ [0.93-1.25], Table 3).

\section{Hospital LOS between Black and White patients}

The proportion of patients with LOS > 10 days was higher for Blacks than Whites (21\% vs. 19\%; OR, 95\% CI = 1.17 [1.16-1.18]). Simple logistic regression analysis revealed the following variables $(P<0.001)$ to be associated with LOS > 10 days: race, survey year, age, gender, insurance status, presence of OI, HBV, HCV, and cocaine use. All variables from the regression analysis were subsequently entered in the multivariable model as covariates. Multivariable analysis identified Black race as an independent predictor for LOS $>10$ days $(\mathrm{OR}, 95 \% \mathrm{CI}=1.20[1.10-$ 1.30], Table 4).

\section{Annual hospital mortality and LOS trends between Black and White patients}

Figure 1 depicts trends in crude hospital mortality for Blacks and Whites from 1996-2006. Although both cohorts exhibited decreases in mortality, the decline for Blacks initially lagged behind that of Whites until 2001, when rates for mortality appeared to have converged between the two races. Crude rates for LOS > 10 days were greater for Blacks at the beginning of the study period, but the rates for the cohorts appeared to converge with time (Figure 2). Figures 3 and 4 reflect the adjusted hospital mortality and LOS trends over the last decade. Similar to the crude rates, the adjusted rates demonstrate the likelihood of hospital mortality and the likelihood for a longer LOS for Blacks were initially higher than that of Whites in 1996, but the odds for both outcomes appeared to decrease with time.

\section{Discussion}

This study compared health outcomes for Black and White HIV/AIDS patients across the United States in the HAART era. Despite the many successes that have resulted 
Table 2: Selected Discharge Characteristics among Blacks vs. Whites

\begin{tabular}{|c|c|c|c|c|}
\hline \multirow[t]{2}{*}{ Characteristic } & \multirow{2}{*}{$\begin{array}{c}\text { Total } \\
(N=1,5|8,| 73)\end{array}$} & \multicolumn{2}{|c|}{ Race } & \multirow[t]{2}{*}{ P-Value } \\
\hline & & $\begin{array}{c}\text { Blacks } \\
(\mathrm{N}=948,666)\end{array}$ & $\begin{array}{c}\text { Whites } \\
(\mathbf{N}=\mathbf{5 6 9 , 5 0 7 )}\end{array}$ & \\
\hline Survey Year & & & & $<0.001$ \\
\hline 1996 & 171,253 & $95,546(10 \%)$ & 75,707 (13\%) & \\
\hline 1997 & 133,493 & $78,665(8 \%)$ & $54,838(10 \%)$ & \\
\hline 1998 & 140,619 & $82,730(9 \%)$ & $57,889(10 \%)$ & \\
\hline 1999 & 125,398 & $78,075(8 \%)$ & $47,323(8 \%)$ & \\
\hline 2000 & 119,673 & $76,629(8 \%)$ & $43,044(8 \%)$ & \\
\hline 2001 & 136,796 & $93,424(10 \%)$ & $43,372(8 \%)$ & \\
\hline 2002 & 134,593 & $83,645(9 \%)$ & $50,948(9 \%)$ & \\
\hline 2003 & 146,975 & 94,379 (10\%) & $52,596(9 \%)$ & \\
\hline 2004 & $149,8 \mid 7$ & $92,883(10 \%)$ & $56,934(10 \%)$ & \\
\hline 2005 & 121,116 & $81,165(9 \%)$ & $39,951(7 \%)$ & \\
\hline 2006 & 138,440 & 91,525 (9\%) & $46,915(8 \%)$ & \\
\hline Age (years) & & & & $<0.001$ \\
\hline $18-34$ & 360,605 & $224,644(24 \%)$ & $|35,96|(24 \%)$ & \\
\hline $35-49$ & 869,517 & $542,349(57 \%)$ & 327,168 (57\%) & \\
\hline $50-64$ & 258,74 I & $164,579(17 \%)$ & $94,162(17 \%)$ & \\
\hline$\geq 65$ & 29,310 & $17,094(2 \%)$ & $12,216(2 \%)$ & \\
\hline Gender & & & & $<0.001$ \\
\hline Male & $1,014,194$ & $562,565(59 \%)$ & $45 \mathrm{I}, 629$ (79\%) & \\
\hline Female & 503,979 & 386,101 (41\%) & II 7,878 (21\%) & \\
\hline Insurance Status & & & & $<0.001$ \\
\hline Uninsured & 135,124 & $88,389(9 \%)$ & $46,735(8 \%)$ & \\
\hline Government & 994,492 & 662,787 (70\%) & 331,705 (58\%) & \\
\hline Private & 341,686 & $167,102(18 \%)$ & $\mid 75,584(3 \mid \%)$ & \\
\hline Other insurance & 46,871 & $30,388(3 \%)$ & $16,483(3 \%)$ & \\
\hline Any Opportunistic Infection (OI) & 406,661 & 255,988 (27\%) & $150,673(26 \%)$ & $<0.001$ \\
\hline Preventable OI & 167,623 & $101,043(11 \%)$ & $66,580(12 \%)$ & $<0.001$ \\
\hline Non-Preventable OI & 301,316 & $196,106(21 \%)$ & $110,210(19 \%)$ & $<0.001$ \\
\hline Hepatitis B & 47,847 & $28,051(3 \%)$ & $19,796(3 \%)$ & $<0.001$ \\
\hline Hepatitis C & $|47,26|$ & $80,295(8 \%)$ & $66,966(12 \%)$ & $<0.001$ \\
\hline Substance Use & 421,591 & $285,133(30 \%)$ & $136,458(24 \%)$ & $<0.001$ \\
\hline STIs & 79,243 & $54,123(6 \%)$ & $25,120(4 \%)$ & $<0.001$ \\
\hline
\end{tabular}

from combating the disease over the past decade, published data suggest that Blacks continue to experience a disproportionate burden of HIV infection. Not only are Blacks overrepresented in the total number of people living with the disease, they continue to experience the highest rates of new infections and AIDS-related deaths [36]. In the general US population, there are approximately 5 times fewer Blacks than Whites. Of the 1.5 million HIV/ AIDS hospital discharges identified in this study, Blacks were 6 times more likely to be hospitalized than Whites, a disparity that has been identified in previous studies conducted after the initiation of HAART $[16,17,37]$. Although the crude mortality rates were similar for Blacks and Whites in the present study, Black race, in the presence of comorbidities, substance use, and socioeconomic status, was associated with longer LOS, but not in-hospital mortality. Furthermore, both mortality and LOS seem to have converged with time. Based on the multivariable regres- 
Table 3: Mortality Predictors from Multivariable Logistic Regression Analysis

\begin{tabular}{|c|c|c|c|}
\hline Characteristic & OR (95\% Cl) & L-R Chi-Square & P-Value \\
\hline Survey Year & & 68.2 & $<0.001$ \\
\hline 1996 & 1.00 (reference) & & \\
\hline 1997 & $1.02(0.63-1.58)$ & & \\
\hline 1998 & $1.25(0.80-1.89)$ & & \\
\hline 1999 & $1.05(0.65-1.65)$ & & \\
\hline 2000 & $0.74(0.43-1.21)$ & & \\
\hline 2001 & $1.19(0.76-1.83)$ & & \\
\hline 2002 & $0.98(0.61-1.54)$ & & \\
\hline 2003 & $1.94(1.29-2.85)$ & & \\
\hline 2004 & $0.59(0.35-0.96)$ & & \\
\hline 2005 & $0.37(0.19-0.66)$ & & \\
\hline 2006 & $0.64(0.38-1.05)$ & & \\
\hline Race & & 0.9 & 0.3 \\
\hline White & 1.00 (reference) & & \\
\hline Black & $1.07(0.93-1.25)$ & & \\
\hline Age (years) & & 12.8 & 0.005 \\
\hline $18-34$ & 1.00 (reference) & & \\
\hline $35-49$ & $0.66(0.51-0.86)$ & & \\
\hline $50-64$ & $0.77(0.55-1.08)$ & & \\
\hline$\geq 65$ & $3.06(1.65-5.37)$ & & \\
\hline Gender & & 2.7 & 0.9 \\
\hline Female & 1.00 (reference) & & \\
\hline Male & $1.14(0.98-1.34)$ & & \\
\hline Insurance Status & & 3.8 & 0.4 \\
\hline Uninsured & 1.00 (reference) & & \\
\hline Government & $0.81(0.63-1.07)$ & & \\
\hline Private & $0.76(0.55-1.04)$ & & \\
\hline Other insurance & $1.57(0.85-2.74)$ & & \\
\hline \multicolumn{4}{|c|}{ Presence of Comorbidities* } \\
\hline Preventable OI & $2.39(2.00-2.83)$ & 86.9 & $<0.001$ \\
\hline Non-preventable OI & $1.16(0.98-1.37)$ & 3.1 & 0.08 \\
\hline HBV & $0.86(0.54-|.3|)$ & 0.5 & 0.5 \\
\hline $\mathrm{HCV}$ & $0.85(0.64-1.11)$ & 1.3 & 0.2 \\
\hline Cocaine use & $0.46(0.32-0.80)$ & 25.2 & $<0.001$ \\
\hline
\end{tabular}

*Reference group is the absence of a comorbidity where $\mathrm{OR}=1.00$

sion models, it is possible that other demographic factors including comorbidities and insurance status may be more predictive of outcome than simply race.

Although HAART is clearly an effective treatment for HIV, the clinical benefits of therapy may not extend equally to patients who are diagnosed with advanced stages of infections $[4,5]$. Thus, the high proportion of patients with OIs was concerning for both study cohorts. Nonetheless,
Black patients demonstrated slightly higher rates of OIs compared to Whites. This study confirmed that the presence of an OI was predictive of higher mortality as well as extended hospitals stays in multivariable regression models. As previously mentioned, Blacks have been reported to seek care later in the course of infection after they are symptomatic from their illness [13-15]. The increased rate of mortality among Blacks has been well documented $[9,16,23,38]$. One such study by Jain and colleagues 
Table 4: Predictors for LOS > 10 days from Multivariable Logistic Regression Analysis

\begin{tabular}{|c|c|c|c|}
\hline Characteristic & OR (95\% CI) & L-R Chi-Square & P-Value \\
\hline Survey Year & & 104.4 & $<0.001$ \\
\hline 1996 & 1.00 (reference) & & \\
\hline 1997 & $1.78(I .4 \mid-2.25)$ & & \\
\hline 1998 & $1.47(1.17-1.86)$ & & \\
\hline 1999 & $0.62(0.47-0.81)$ & & \\
\hline 2000 & $0.94(0.72-1.22)$ & & \\
\hline 2001 & $0.91(0.7 I-1.17)$ & & \\
\hline 2002 & $0.91(0.71-1.17)$ & & \\
\hline 2003 & $1.07(0.85-1.36)$ & & \\
\hline 2004 & $0.74(0.58-0.95)$ & & \\
\hline 2005 & $0.65(0.49-0.86)$ & & \\
\hline 2006 & $0.72(0.56-0.93)$ & & \\
\hline Race & & 18.4 & $<0.001$ \\
\hline White & 1.00 (reference) & & \\
\hline Black & $1.20(1.10-1.30)$ & & \\
\hline Age & & 26.4 & $<0.001$ \\
\hline $18-34$ & 1.00 (reference) & & \\
\hline $35-49$ & $0.98(0.83-1.17)$ & & \\
\hline $50-64$ & $1.34(1.09-1.64)$ & & \\
\hline$\geq 65$ & $1.10(0.70-1.67)$ & & \\
\hline Gender & & 0.3 & 0.6 \\
\hline Female & 1.00 (reference) & & \\
\hline Male & $1.02(0.94-1.11)$ & & \\
\hline Insurance Status & & 8.4 & 0.04 \\
\hline Uninsured & 1.00 (reference) & & \\
\hline Government & $1.22(1.04-1.43)$ & & \\
\hline Private & $0.96(0.80-1.16)$ & & \\
\hline Other insurance & $0.89(0.62-1.27)$ & & \\
\hline \multicolumn{4}{|c|}{ Presence of Comorbidities* } \\
\hline Preventable OI & $1.97(1.77-2.20)$ & 142.9 & $<0.001$ \\
\hline Non-preventable OI & $2.03(1.86-2.22)$ & 238.0 & $<0.001$ \\
\hline HBV & $1.05(0.84-1.31)$ & 0.2 & 0.7 \\
\hline $\mathrm{HCV}$ & $1.04(0.90-1.19)$ & 0.3 & 0.6 \\
\hline Cocaine use & $0.98(0.93-1.12)$ & 0.1 & 0.8 \\
\hline
\end{tabular}

$*$ Reference group is the absence of a comorbidity where OR $=1.00$

reported poorer outcomes among patients with OIs, specifically highlighting the elevated risk for Black patients [34]. The Jain study differs from the present study in that the investigators were unable to evaluate comorbidities, and various forms of substance use.

Baseline rates of substance use were higher among Blacks than Whites. The rate of cocaine use for Blacks was almost three times that of Whites; interestingly, regression analy- sis revealed cocaine use was 'protective' for mortality, perhaps because cocaine use was also associated with younger age. Nevertheless, studies suggest illicit drug use may have a negative impact on the treatment and course of HIV/AIDS infection $[39,40]$. Concomitant use of illicit substances may also interfere with a patients' ability to adhere to antiretroviral regimens, thereby placing them at risk for poorer health outcomes [23,39,40]. Cocaine has been demonstrated in vitro and in experimental animal 


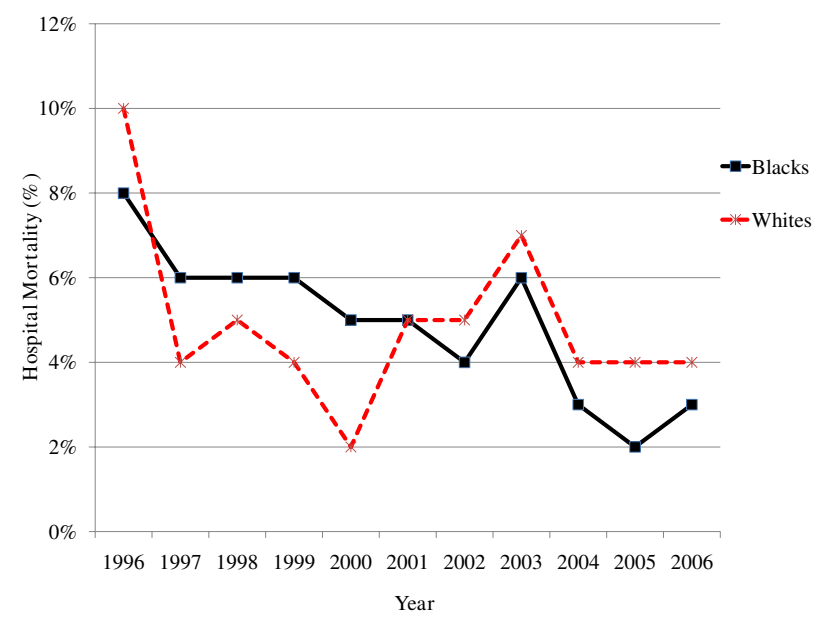

Figure I

Crude hospital mortality for Black and White HIVI AIDS patients from 1996-2006.

models to enhance viral replication and interfere with the body's ability to defend itself naturally against infection. This may hasten disease progression and the development of AIDS-defining conditions, even among patients who are adherent to antiretroviral therapy [41-43]. However, definitive data directly implicating illicit drug use as a causative factor in increased HIV susceptibility or disease progression remain elusive [41]. Of the various types of substance use in this study, cocaine use was the most likely form of injection drug use, which has also been implicated in the transmission of not only HIV, but also

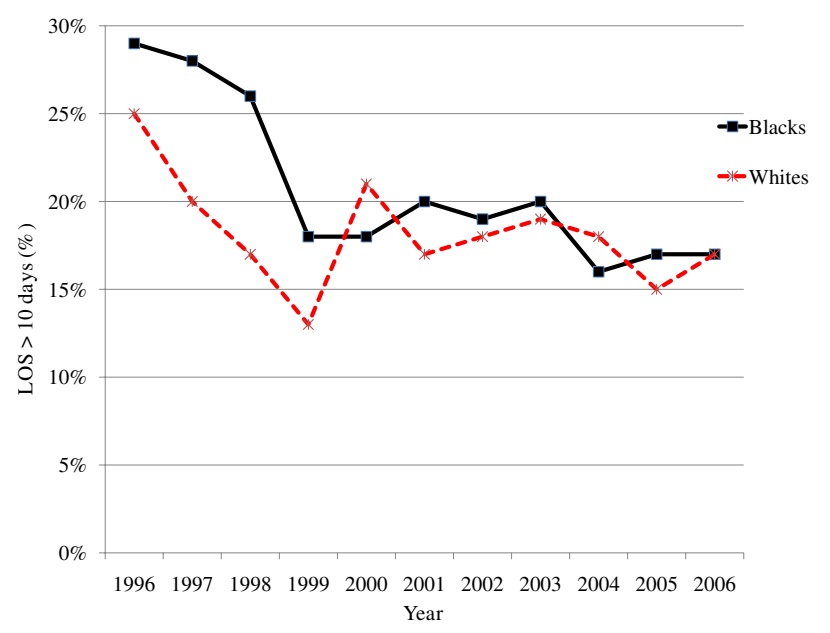

Figure 2

Crude LOS > I 0 days for Black and White HIVIAIDS patients from 1996-2006.
Blacks less Blacks more

likely to die likely to die

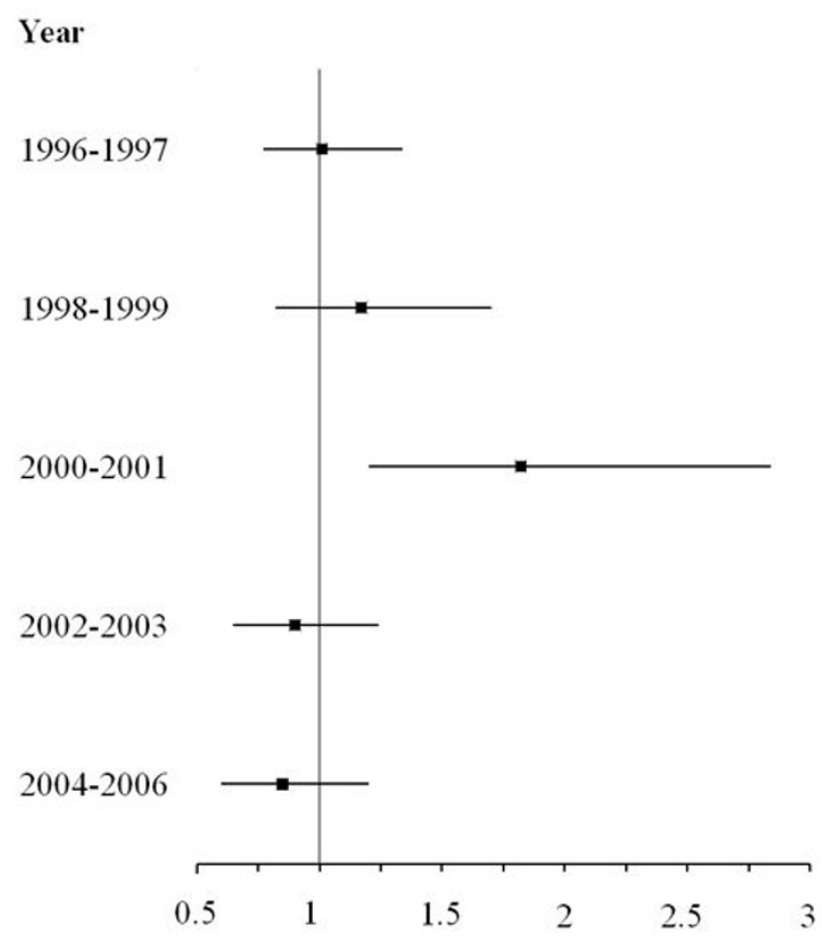

Odds Ratio for Hospital Mortality (Blacks vs. Whites)

Figure 3

Adjusted hospital mortality for Black vs. White HIVI AIDS patients from 1996-2006 (Odds Ratio, 95\%

CI)*. *Odds ratios were calculated from the multivariable logistic regression model.

HBV and HCV, particularly among minority populations [23-25].

Beyond the HIV/AIDS population, other racial disparities exist for Blacks; they tend to have higher rates of HBV and HCV compared to Whites [24,25,44]. Furthermore, response to therapy for $\mathrm{HCV}$ is markedly diminished for Blacks [45]. Interestingly, in the present study the rates of HBV coinfection were similar among both study cohorts and HCV coinfection rates were lower for Blacks than for Whites. Although hepatitis coinfection is associated with increased mortality, the true rates of HIV/HCV coinfection and its implications for health outcomes among Black populations remain ill-defined $[26,46]$.

Likewise, the national impact of race disparities among individuals with concomitant STIs is not well-characterized [47]. The increased risk for contracting HIV with 
Blacks less likely to Blacks more likely to have $\operatorname{LOS}>10$ days have $\operatorname{LOS}>10$ days

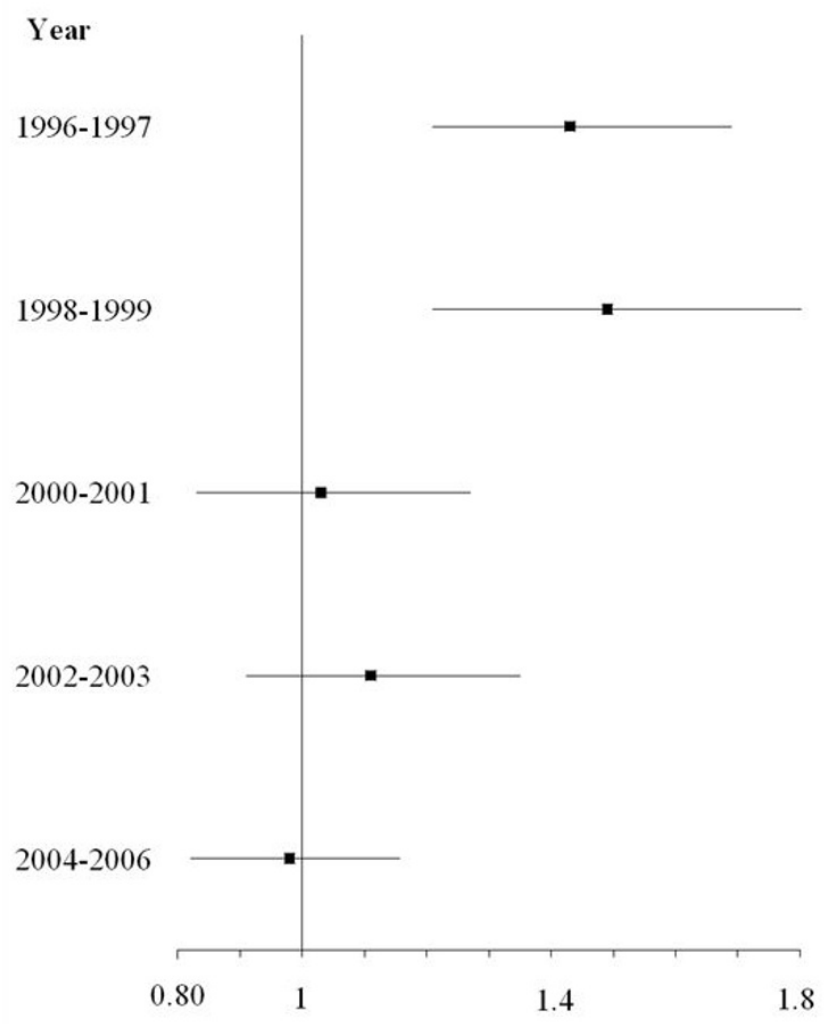

Odds Ratio for LOS $>10$ days (Blacks vs. Whites)

\section{Figure 4}

Adjusted LOS > 10 days for Black vs. White HIVI AIDS patients from 1996-2006 (Odds Ratio, 95\%

CI)*. *Odds ratios were calculated from the multivariable logistic regression model.

simultaneous STIs (both ulcerative and non ulcerative) has been well established [47-50]. HIV, coupled with infections such as syphilis, may negatively impact the immune status of the individual and may lead to higher rates of treatment failure $[19,51,52]$. Furthermore, genital herpes, gonorrhea, chlamydia, syphilis, bacterial vaginosis and chancroid, are reportedly higher in minority populations [47]. In the present study, reported rates of STIs were relatively low in both groups of hospitalized patients. Complications from STIs including severe herpes simplex virus, syphilis with neurologic involvement, and acute pelvic inflammatory may require aggressive treatment necessitating hospitalization, whereas most other STIs can be managed effectively in the ambulatory setting [53]. Therefore, STIs were not included in regression analyses. Definitive conclusions regarding STIs could not be made from this cohort of hospitalized patients. Nevertheless, a higher percentage of Blacks carried an STI ICD-9 diagnosis.

A surprising, but fortunate finding from this study is the possibility that racial disparities in hospital outcomes may be closing with time. This possible reduction in racial disparities in outcome has been demonstrated elsewhere $[8,37,54,55]$. Similar to the Giordano and Hlaing studies, this study was not able to incorporate antiretroviral use in the regression analysis [37,55]. Antiretrovirals, if prescribed properly, may reduce differences in outcomes between Blacks and Whites $[8,54]$. Yet, in stark contrast, Jain and colleagues concluded that the disparity for higher mortality for Black HIV patients has actually widened in the HAART era [34]. According to their results, the elevated risk of a poor outcome was also attributable to the presence of an opportunistic infection, a finding that is consistent with the present study. Another study by Levine and colleagues also substantiates these findings. They identified that higher rates of mortality existed among Black males both before and after the introduction of HAART [9]. The investigators lacked data for comorbid conditions and also did not evaluate hospitalized patients. The current study evaluated all-cause hospital mortality, whereas the two studies that concluded Blacks were at increased risk for mortality used surveillance data and a combination of inpatient and outpatient data [56,57]. The present study had the most patient records and the longest duration of any of the studies identified in the literature review.

This study shares the limitations of all retrospective cohort studies. In addition, the analysis was limited by the lack of available clinical variables, including medication information, time of HIV diagnosis, and objective clinical markers of disease progression. Therefore, we could not assess the relationships between quality of care indicators and patient outcomes. Additionally, management of acute HBV, HCV, and STIs may not require hospitalization. These data are also limited by proxies for racism and discrimination that are known predictors of raciallybiased outcomes. These variables are important when describing disparities and could have at least partly explained the racial variations and/or non-variations found in this study. The data source lacks information regarding patients of Hispanic descent; therefore, we were unable to draw conclusions about health disparities for this minority group that is also facing a disproportionate burden of HIV [36]. Another limitation is that patients who were admitted for less than one day, or who left the hospital against medical advice were excluded from the analysis. It is possible these patients ultimately suffered suboptimal health outcomes (early mortality). The survey scope encompassed only non-federal hospitals, so the 
results may not be applicable to HIV/AIDS patients admitted to other US hospitals, such as the Veterans Healthcare Administration. Finally, several other complex socioeconomic issues that may affect health outcomes were not evaluated in this study.

\section{Conclusion}

This study characterized the rates of comorbid conditions, hospital mortality and LOS, and evaluated trends in health outcomes among Black and White HIV/AIDS patients over a decade. Some disparities may still persist despite the availability of effective interventions to reduce morbidity and mortality. This national assessment of hospital discharges demonstrates that Black race may be predictive of longer LOS, but not mortality. In addition, disparities in health outcomes may be decreasing with time. Further research efforts are warranted to recognize and clarify the complexities facing the Black HIV/AIDS population in order to reduce health disparities.

\section{Abbreviations}

HAART: highly active antiretroviral therapy; HIV: Human Immunodeficiency Virus; AIDS: Acquired Immunodeficiency Syndrome; LOS: length of hospital stay; CI: confidence interval; OR: odds ratio; L-R likelihood ratio; OI: opportunistic infection; STI: sexually transmitted infection.

\section{Competing interests}

The authors declare that they have no competing interests.

\section{Authors' contributions}

CUO had full access to the data in the study and assisted with the study design, study concepts, data analysis and interpretation, and drafting of the manuscript. CRF directed and supervised all aspects of the study from its conception to the finalization of the manuscript. JMH assisted in drafting the manuscript. JS assisted in the statistical analysis and interpretation of data, as well as critical revision of the manuscript for important intellectual content. All authors assisted with critical revision of the manuscript for important intellectual content, and have approved the final manuscript.

\section{Acknowledgements}

The authors would like to thank Alice Pau, Vivek Gopalan, and Kyllie RyanHummel for their assistance with this manuscript. This study was supported by new faculty start-up funds granted to Dr. Frei and a Graduate Diversity Mentoring Fellowship granted to Dr. Oramasionwu from the University of Texas at Austin. The authors have no financial conflicts of interest to disclose related to the content of this paper.

\section{References}

I. Hall HI, Song R, Rhodes P, Prejean J, An Q, Lee LM, Karon J, Brookmeyer R, Kaplan EH, McKenna MT, Janssen RS: Estimation of HIV incidence in the United States. JAMA 2008, 300:520-529.
2. Centers for Disease Control and Prevention: HIVIAIDS Surveillance Report, 2007. 2009, 19: I-63 [http://www.cdc.gov/hiv/topics/ surveillance/resources/reports/]. Atlanta, GA: US Department of Health and Human Services, Centers for Disease Control and Prevention Accessed March 22, 2009

3. Fischl MA, Richman DD, Grieco MH, Gottlieb MS, Volberding PA, Laskin OL, Leedom JM, Groopman JE, Mildvan D, Schooley RT: The efficacy of azidothymidine (AZT) in the treatment of patients with AIDS and AIDS-related complex. A doubleblind, placebo-controlled trial. N Engl J Med I987, 3 I 7: 185-191.

4. Palella FJ Jr, Baker RK, Moorman AC, Chmiel JS, Wood KC, Brooks JT, Holmberg SD: Mortality in the highly active antiretroviral therapy era: changing causes of death and disease in the HIV outpatient study. J Acquir Immune Defic Syndr 2006, 43:27-34.

5. Palella FJ Jr, Delaney KM, Moorman AC, Loveless MO, Fuhrer J, Satten GA, Aschman DJ, Holmberg SD: Declining morbidity and mortality among patients with advanced human immunodeficiency virus infection. HIV Outpatient Study Investigators. N Engl J Med I998, 338:853-860.

6. Blair JM, Fleming PL, Karon JM: Trends in AIDS incidence and survival among racial/ethnic minority men who have sex with men, United States, I 990-1 999. J Acquir Immune Defic Syndr 2002, 3 I:339-347.

7. Nakashima AK, Fleming PL: HIVIAIDS surveillance in the United States, I 98I-2001. J Acquir Immune Defic Syndr 2003, 32(Suppl I):68-85.

8. Lemly DC, Shepherd BE, Hulgan T, Rebeiro P, Stinnette S, Blackwell RB, Bebawy S, Kheshti A, Sterling TR, Raffanti SP: Race and sex differences in antiretroviral therapy use and mortality among HIV-Infected persons in care. J Infect Dis 2009, I 99:991-998.

9. Levine RS, Briggs NC, Kilbourne BS, King WD, Fry-Johnson Y, Baltrus PT, Husaini BA, Rust GS: Black-White mortality from HIV in the United States before and after introduction of highly active antiretroviral therapy in 1996. Am J Public Health 2007, 97:1884- 1892.

10. Keruly JC, Moore RD: Immune status at presentation to care did not improve among antiretroviral-naive persons from 1990 to 2006. Clin Infect Dis 2007, 45:1369-74.

II. Late versus early testing of HIV - 16 Sites, United States, 2000-2003. MMWR Morb Mortal Wkly Rep 2003, 52:58I-586.

12. Turner BJ, Cunningham WE, Duan N, Andersen RM, Shapiro MF, Bozzette SA, Nakazono T, Morton S, Crystal S, St Clair P, Stein M, Zierler $S$ : Delayed medical care after diagnosis in a US national probability sample of persons infected with human immunodeficiency virus. Arch Intern Med 2000, 160:26|4-2622.

13. Hellinger FJ: The changing pattern of hospital care for persons living with HIV: 2000 through 2004. J Acquir Immune Defic Syndr 2007, 45:239-246.

14. Hellinger FJ, Fleishman JA: Location, race, and hospital care for AIDS patients: an analysis of 10 states. Inquiry 200I, 38:319-330.

15. Bonuck KA, Arno PS: Social and medical factors affecting hospital discharge of persons with HIVIAIDS. J Community Health 1997, 22:225-232.

16. Gebo KA, Fleishman JA, Moore RD: Hospitalizations for metabolic conditions, opportunistic infections, and injection drug use among HIV patients: trends between 1996 and 2000 in 12 states. J Acquir Immune Defic Syndr 2005, 40:609-6I6.

17. Fleishman JA, Gebo KA, Reilly ED, Conviser R, Christopher Mathews W, Todd Korthuis P, Hellinger J, Rutstein R, Keiser P, Rubin H, Moore RD: Hospital and outpatient health services utilization among HIV-infected adults in care 2000-2002. Med Care 2005, 43:III40-III52.

18. Oramasionwu CU, Skinner J, Ryan L, Frei CR: Disparities in antiretroviral prescribing for Blacks and Whites in the United States. J Natl Med Assoc 2009 in press.

19. Fenton KA, Breban R, Vardavas R, Okano JT, Martin T, Aral S, Blower S: Infectious syphilis in high-income settings in the 2 I st century. Lancet Infect Dis 2008, 8:244-253.

20. Alazawi W, Foster GR: Advances in the diagnosis and treatment of hepatitis B. Curr Opin Infect Dis 2008, 2 I :508-5 I 5.

21. De Alba I, Samet JH, Saitz R: Burden of medical illness in drugand alcohol-dependent persons without primary care. $\mathrm{Am} J$ Addict 2004, 13:33-45. 
22. Centers for Disease Control and Prevention: Disease Burden from Hepatitis A, B, and C in the United States. [http:// www.cdc.gov/hepatitis/Statistics.htm\#section3].

23. Hall HI, McDavid K, Ling Q, Sloggett A: Determinants of progression to AIDS or death after HIV diagnosis, United States, 1996 to 200I. Ann Epidemiol 2006, 16:824-833.

24. Estrada AL: Epidemiology of HIVIAIDS, hepatitis B, hepatitis $C$, and tuberculosis among minority injection drug users. Public Health Rep 2002, I I 7:126-134.

25. Estrada AL: Health disparities among African-American and Hispanic drug injectors - HIV, AIDS, hepatitis B virus and hepatitis C virus: a review. AIDS 2005, 19:47-52.

26. Monga HK, Rodriguez-Barradas MC, Breaux K, Khattak K, Troisi CL, Velez M, Yoffe B: Hepatitis C virus infection-related morbidity and mortality among patients with human immunodeficiency virus infection. Clin Infect Dis 200I, 33:240-247.

27. National Center for Health Statistics: National hospital discharge survey description. [http://www.cdc.gov/nchs/about/major/hdasd/ nhdsdes.htm].

28. Gupta RS, Carrion-Carire V, Weiss KB: The widening black/white gap in asthma hospitalizations and mortality. J Allergy Clin Immunol 2006, II 7:35I-358.

29. Stein PD, Beemath A, Meyers FA, Skaf E, Sanchez J, Olson RE: Incidence of venous thromboembolism in patients hospitalized with cancer. Am J Med 2006, 1 1 9:60-68.

30. Kennedy BS, Kasl SV, Brass LM, Vaccarino V: Trends in hospitalized stroke for blacks and whites in the United States, 1980 1999. Neuroepidemiology 2002, 21 : | 31 - I4I.

31. Centers for Disease Control and Prevention: 1993 revised classification system for HIV infection and expanded surveillance case definition for AIDS among adolescents and adults. MMWR Recomm Rep 1992, 41:1-19.

32. Benson CA, Kaplan JE, Masur H, Pau A, Holmes KK: Treating opportunistic infections among HIV-infected adults and adolescents: recommendations from CDC, the National Institutes of Health, and the HIV Medicine Association/Infectious Diseases Society of America. MMWR Recomm Rep 2004 53:I-II2.

33. Guidelines for Prevention and Treatment of Opportunistic Infections in HIV-Infected Adults and Adolescents. MMWR Morb Mortal Wkly Rep 2009, 58: I-198.

34. Jain S, Schwarcz S, Katz M, Gulati R, McFarland W: Elevated risk of death for African Americans with AIDS, San Francisco, 1996-2002. J Health Care Poor Underserved 2006, 17:493-503.

35. McFarland W, Chen S, Hsu L, Schwarcz S, Katz M: Low socioeconomic status is associated with a higher rate of death in the era of highly active antiretroviral therapy, San Francisco. Acquir Immune Defic Syndr 2003, 33:96-103.

36. Centers for Disease Control and Prevention: Racial/ethnic disparities in diagnoses of HIVIAIDS - 33 states, 200I-2005. MMWR Morb Mortal Wkly Rep 2007, 56: 189-193.

37. Hlaing WM, McCoy HV: Differences in HIV-related hospitalization among white, black, and Hispanic men and women of Florida. Women Health 2008, 47: I- I8.

38. Chiu YW, Hsu CE, Wang MQ, Nkhoma ET: Examining geographic and temporal variations of AIDS mortality: evidence of racial disparities. J Natl Med Assoc 2008, 100:788-796.

39. Bing EG, Burnam MA, Longshore D, Fleishman JA, Sherbourne CD, London AS, Turner BJ, Eggan F, Beckman R, Vitiello B, Morton SC Orlando M, Bozzette SA, Ortiz-Barron L, Shapiro M: Psychiatric disorders and drug use among human immunodeficiency virus-infected adults in the United States. Arch Gen Psychiatry 200I, 58:72I-728.

40. Lucas GM, Cheever LW, Chaisson RE, Moore RD: Detrimental effects of continued illicit drug use on the treatment of HIV. I infection. J Acquir Immune Defic Syndr 200I, 27:25I-259.

4I. Cabral GA: Drugs of abuse, immune modulation, and AIDS. Neuroimmune Pharmacol 2006, I:280-295.

42. Vittinghoff E, Hessol NA, Bacchetti P, Fusaro RE, Holmberg SD, Buchbinder SP: Cofactors for HIV disease progression in a cohort of homosexual and bisexual men. J Acquir Immune Defic Syndr 200I, 27:308-314.

43. Cook JA, Burke-Miller JK, Cohen MH, Cook RL, Vlahov D, Wilson TE, Golub ET, Schwartz RM, Howard AA, Ponath C, Plankey MW Levine AM, Grey DD: Crack cocaine, disease progression, and mortality in a multicenter cohort of HIV-I positive women. AIDS 2008, 22: I355-I363.

44. McQuillan GM, Coleman PJ, Kruszon-Moran D, Moyer LA, Lambert $\mathrm{SB}$, Margolis HS: Prevalence of hepatitis B virus infection in the United States: the National Health and Nutrition Examination Surveys, 1976 through 1994. Am J Public Health 1999, 89: I4-I8.

45. Muir AJ, Bornstein JD, Killenberg PG: Peginterferon alfa-2b and ribavirin for the treatment of chronic hepatitis $\mathbf{C}$ in blacks and non-Hispanic whites. N Engl J Med 2004, 350:2265-227I.

46. Merriman NA, Porter SB, Brensinger CM, Reddy KR, Chang KM: Racial difference in mortality among US veterans with $\mathrm{HCV}$ I HIV coinfection. Am J Gastroenterol 2006, I0I:760-767.

47. Centers for Disease Control and Prevention: Sexually transmitted disease surveillance. 2006. Atlanta, GA: US Department of Health and Human Services; 2007.

48. Fleming DT, Wasserheit JN: From epidemiological synergy to public health policy and practice: the contribution of other sexually transmitted diseases to sexual transmission of HIV infection. Sex Transm Infect 1999, 75:3-17.

49. Wasserheit JN: Epidemiological synergy. Interrelationships between human immunodeficiency virus infection and other sexually transmitted diseases. Sex Transm Dis 1992, 19:6I-77.

50. Wu JJ, Huang DB, Pang KR, Tyring SK: Selected sexually transmitted diseases and their relationship to HIV. Clin Dermatol 2004, 22:499-508

5I. Palacios R, Jimenez-Onate F, Aguilar M, Galindo MJ, Rivas P, Ocampo A, Berenguer J, Arranz JA, Rios MJ, Knobel H, Moreno F, Ena J, Santos J: Impact of syphilis infection on HIV viral load and CD4 cell counts in HIV-infected patients. I Acquir Immune Defic Syndr 2007, 44:356-359.

52. Buchacz K, Patel P, Taylor M, Kerndt PR, Byers RH, Holmberg SD, Klausner JD: Syphilis increases HIV viral load and decreases CD4 cell counts in HIV-infected patients with new syphilis infections. AIDS 2004, I 8:2075-2079.

53. Centers for Disease Control and Prevention: Sexually transmitted diseases treatment guidelines, 2006. MMWR Recomm Rep 2006 , 55(RR-I I): I-94

54. Cunningham WE, Markson LE, Andersen RM, Crystal SH, Fleishman JA, Golin C, Gifford A, Liu HH, Nakazono TT, Morton S, Bozzette SA Shapiro MF, Wenger NS: Prevalence and predictors of highly active antiretroviral therapy use in patients with HIV infection in the united states. HCSUS Consortium. HIV Cost and Services Utilization. J Acquir Immune Defic Syndr 2000, 25: I I 5- I 23.

55. Giordano TP, Morgan RO, Kramer JR, Hartman C, Richardson P, White CA Jr, Suarez-Almazor ME, El-Serag HB: Is there a racebased disparity in the survival of veterans with HIV? J Gen Intern Med 2006, 21:613-617.

56. McGinnis KA, Fine MJ, Sharma RK, Skanderson M, Wagner JH, Rodriguez-Barradas MC, Rabeneck L, Justice AC: Understanding racial disparities in HIV using data from the veterans aging cohort 3-site study and VA administrative data. Am J Public Health 2003, 93:1728-1733.

57. Nash D, Katyal M, Shah S: Trends in predictors of death due to HIV-related causes among persons living with AIDS in New York City: 1993-200I. J Urban Health 2005, 82:584-600.

\section{Pre-publication history}

The pre-publication history for this paper can be accessed here:

http://www.biomedcentral.com/1471-2334/9/127/pre pub 